\title{
Correction to: Is magnetic resonance imaging needed for decision making diagnosis and treatment of thoracic and lumbar vertebral fractures?
}

\author{
Published online: 25 January 2022 \\ c) Springer-Verlag France SAS, part of Springer Nature 2022

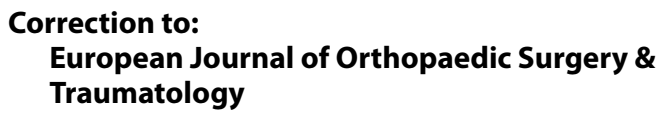

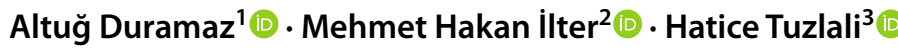

The original version of this article unfortunately contained a mistake. Author name Altuğ Duramaz was incorrectly written as Altuğ Durmaz.

Publisher's Note Springer Nature remains neutral with regard to jurisdictional claims in published maps and institutional affiliations.

The original article can be found online at https://doi.org/10.1007/ s00590-021-03165-z.

Altuğ Duramaz

altug.duramaz@yahoo.com

Mehmet Hakan İlter

dr.hakan.ilter@gmail.com

Hatice Tuzlali

haticetuzlali@yahoo.com

1 Department of Orthopedics and Traumatology, Bakırköy Dr. Sadi Konuk Education and Research Hospital, Tevfik Sağlam St. Number 11, Bakırkö, 34147 Istanbul, Turkey

2 Department of Orthopedics and Traumatology, Letoon Hospital, Pazaryeri St., Küçükçoban Ave, Number 22, 48300 Fethiye/Muğla, Turkey

3 Department of Radiology, Wexham Park Hospital, Wexham Street, Slough Berkshire, London, UK 